\title{
0 papel do locus de controlo na relação entre a liderança situacional e a satisfação
}

\author{
Ana Frade Cancelino ${ }^{1}$, Ana Moreira ${ }^{1}$, Pedro Marques-Quinteiro ${ }^{2}$ \& Pedro Almeida ${ }^{1}$ \\ ${ }^{1}$ ISPA - Instituto Universitário \\ ${ }^{2} I S P A$ - Instituto Universitário, William James Center for Research
}

\begin{abstract}
Resumo: 0 presente artigo tem como objetivo estudar a relação entre a liderança situacional e a satisfação com a chefia direta, assim como o efeito mediador do locus de controlo nesta relação. A amostra do presente estudo é composta por 149 trabalhadores recrutados através do método snowball. Todos os participantes reportaram ter supervisão direta. Os resultados sugerem que existe uma relação positiva entre a liderança situacional e a satisfação com o supervisor que não é mediada pelo locus de controlo externo, de tal forma que $\mathrm{B}=0,04, \mathrm{SE}=0,04$, IC 95\% $[-0,05 ; 0,13]$. No entanto esta relação é mediada pelo locus de controlo interno, de tal forma que $\mathrm{B}=0,12, S E=0,05$, IC 95\% $[0,04 ; 0,23]$. 0s resultados deste estudo vêm ajudar a perceber o processo através do qual os comportamentos de liderança das chefias diretas se relacionam com o desenvolvimento de atitudes positivas por parte dos colaboradores no local de trabalho.
\end{abstract}

Palavras-chave: Liderança situacional; liderança transformacional; liderança transacional; satisfação com o supervisor; locus de controlo.

The role of the locus of control in the relationship between situational leadership and satisfaction. The present study intends to explore the relationship between situational leadership and satisfaction with direct leadership, and how employees' locus of control contributes to this same relationship. The study's sample is composed of 149 workers selected via snowball recruitment. All participants reported they worked under a direct supervisor. The results suggest that there is a positive relationship between situational leadership and satisfaction with the supervisor that is not mediated by an external control locus, with $\mathrm{B}=.05, \mathrm{SE}=.07,95 \% \mathrm{CI}[-090, .189]$. This relationship, however, is apparently mediated by an internal locus of control, with $\mathrm{B}=.18 \mathrm{SE}=.06,95 \% \mathrm{CI}[0.070,0.321]$. The results of this study assist in comprehending the process by which leadership behavior of one's direct superior is related to the development of employees' attitudes in the workplace.

Keywords: Situational leadership; transformational leadership; transactional leadership; supervisor satisfaction; locus of control.

Em contexto organizacional, a liderança é fundamental para o funcionamento dos indivíduos, equipas e organizações (Avolio et al., 2009). Com efeito, várias meta-análises têm demonstrado de forma consistente uma relação positiva entre a liderança e indicadores chave do desempenho em contexto organizacional, como por exemplo a produtividade, o bem-estar e a satisfação (Kovjanic et al., 2013).

Os vários estudos realizados sobre esta temática têm dado particular atenção à liderança transformacional e à liderança transacional, enquanto traços dos líderes (Avolio et al., 2009; Saleem, 2015). Sobre as mesmas, uma parte substancial da literatura tem procurado determinar qual destes estilos de liderança tem maior impacto nos comportamentos, afetos e cognições dos colaboradores e em que circunstâncias uma destas formas de liderança se torna mais eficaz do que a outra (Gomes \& Cruz, 2007). Embora o número de contribuições seja menor, existe uma segunda abordagem, segundo a qual a liderança transformacional e a liderança transacional não podem ser pensadas como formas antagónicas de liderança, mas antes formas complementares que coexistem num mesmo indivíduo (Smith, 2015; Tyssen et al., 2013).

Esta visão de que a liderança transformacional e a liderança transacional devem ser pensadas enquanto traços de liderança de uma mesma pessoa assenta na ideia situacional, em que uma liderança eficaz é aquela em que o líder adapta os seus comportamentos ao contexto/situação (Marques-Quinteiro, 2014). A teoria da liderança situacional tem como base uma compreensão racional da situação por parte do líder, ou seja, trata-se de um processo de influência em que o líder monitoriza o contexto

${ }^{1}$ Morada de correspondência: Ana Cancelino, Rua Jardim do Tabaco, no 34, 1100-287 Lisboa. E-mail: anafcancelino@gmail.com 
organizacional e a performance dos colaboradores, determinando conscientemente o comportamento de liderança mais adequado (Grint, 2011). Segundo a teoria da liderança situacional, é expectável que um líder seja capaz de adequar a sua forma de liderar às necessidades dos colaboradores, ajudando não só a que estes tenham um melhor desempenho na tarefa, como a fazer com que se sintam mais satisfeitos em relação à chefia direta (Avolio et al., 2009).

Segundo Epitropaki e Martin (2013), variáveis como a satisfação dos colaboradores face à liderança podem ser determinadas não só pelo estilo de liderança adotado pela chefia direta, como também por características individuais dos colaboradores, como, por exemplo, o locus do controlo (Farmer et al., 1997). Com efeito, sabemos hoje que as características e traços dos indivíduos no contexto organizacional influenciam a natureza e qualidade das relações interpessoais que se estabelecem ao longo do tempo (Runyon, 1973). Por exemplo, diferentes estilos de liderança podem estar relacionados com um locus de controlo interno vs. externo, influenciando de forma diferente o modo como os colaboradores percecionam a qualidade da sua relação com a chefia direta.

Embora existam alguns estudos dispersos que sugerem uma relação entre a liderança situacional, a emergência de características individuais dos colaboradores e a satisfação (Kovjanic et al., 2013; Saleem, 2015), pouco ou nada se sabe acerca da forma como características como o locus de controlo contribuem para ajudar a explicar a relação entre a liderança situacional e a satisfação face à chefia direta. Neste artigo, partimos de estudos recentes sobre a variabilidade intra-individual de atributos psicológicos como a personalidade (e.g., O'Meara \& South, 2019) para testar um modelo de mediação paralela com base na sequência de causalidade Input-Processo-Output (IPO; McGrath, 1964). Nesta análise avaliou-se de que modo a emergência das duas facetas do locus de controlo dos colaboradores poderá ter um papel mediador na relação entre os comportamentos de liderança situacional da chefia direta (input) e a satisfação face à chefia direta (output). Segundo McGrath (1964), o processo é uma definição suficientemente abrangente para descrever as interações, características, comportamentos, afetos e cognições que determinam a natureza da relação entre os inputs e os outputs. Embora estáveis, atributos como o locus de controlo podem tornar-se mais ou menos manifestos e exercer algum tipo de influência sobre outras variáveis, quando influenciados por fatores contextuais do ambiente de trabalho como o estilo de liderança da chefia direta (e.g., Kovjanic et al., 2013). Ainda nesta linha, os resultados de um estudo recente realizado por Rahman (2018) sugerem que o locus de controlo dos colaboradores tem um papel mediador na relação entre o estilo de liderança da chefia direta e a satisfação com a função. Estes resultados suportam a hipótese geral de investigação deste estudo de que o locus de controlo dos colaboradores terá um papel mediador da relação entre a liderança situacional e a satisfação com a chefia direta.

Assim, este estudo contribui para a literatura organizacional de três formas: (1) procura corroborar a hipótese de que a liderança eficaz não é aquela em que o líder adota um único estilo de liderança, mas sim quando o líder adapta os seus comportamentos de liderança ao contexto/situação; (2) estuda a relação entre a liderança situacional e os níveis de satisfação dos colaboradores face ao líder; (3) sugere que os comportamentos de liderança da chefia direta estão relacionados com a forma como características individuais dos colaboradores, como o locus de controlo, se manifestam.

\section{Liderança situacional}

No que respeita à liderança situacional (LS), pode-se traçar a origem deste construto como estando associado à abordagem contingencial de Fiedler (1964), a qual defende que o resultado do estilo de liderança a ser utilizado sobre os colaboradores depende da situação em que estes se encontram, sendo esta conceptualização corroborada por vários autores (Marques-Quinteiro, 2014; Pina e Cunha et al., 2014). Na perspetiva de Pina e Cunha et al., (2014), em situações de baixa e elevada favorabilidade, os líderes que estejam mais orientados para as tarefas serão mais eficazes do que os líderes mais orientados para o relacionamento, enquanto numa situação moderadamente favorável ocorre o inverso.

Uma revisão de literatura aprofundada, realizada por Graeff (1997), analisou dezenas de estudos e artigos tendo concluído que não existe um consenso alargado sobre a definição teórica do conceito, que persistem inconsistências nas abordagens empíricas e não é claro de que se trate de um modelo ou teoria. Esta inconsistência persiste até aos dias de hoje, o que sugere a necessidade de se continuar a investigar sobre estes temas (e.g., Thompson \& Vecchio, 2009).

Dentro da teoria da liderança situacional, Bass (1985) e posteriormente Judge e Piccolo (2004), sugerem que, graças à sua complementaridade, os dois estilos de liderança são eficazes: a liderança transformacional e a liderança transacional. 0 estilo transformacional é mais adequado em alturas de crescimento e de mudança, sendo o estilo transacional mais adequado em períodos de evolução lenta e ambientes estáveis (Bass, 1985). Smith (2015), por seu turno, julga o estilo de liderança transacional eficaz, mas limitado em determinadas situações, podendo ser usada a abordagem da liderança 
transformacional para ultrapassar estas mesmas limitações. Segundo Tyssen et al., (2013), os dois estilos de liderança podem ser eficazes, dependendo das pessoas com quem se trabalha e do momento que a organização vive. Em tempos de crescimento e mudança, a liderança transformacional afeta de forma positiva os colaboradores, no entanto em situações de pressão, como por exemplo a entrega de projetos com prazos, a liderança transacional é mais eficaz. Tal avaliação é pertinente e útil no presente estudo por equacionar a coexistência de ambas as abordagens no input de liderança situacional.

Liderança Transformacional. A liderança transformacional é caracterizada como um processo de liderança que leva a alterações ao nível das atitudes e comportamentos praticados pelos colaboradores (Burns, 1978; Bass et al., 2003). A principal preocupação dos líderes transformacionais consiste em aumentar a consciência dos seus colaboradores de que o compromisso e a empatia são essenciais para que todos consigam alcançar os seus objetivos (Burns, 1978). Neste sentido, o líder transformacional leva a que os seus seguidores desempenhem as suas funções com o foco mais além do que os objetivos a curto prazo através da influência que exerce, conseguindo aumentar os níveis de maturidade, os ideais, assim como estimular a existência de preocupações com a autorrealização de cada colaborador (Bass, 1999). Para Kovjanic et al., (2013), os líderes transformacionais ao ajudarem os seus colaboradores a desenvolver técnicas individuais para ultrapassarem os seus problemas, estão a criar um ambiente ideal para o desenvolvimento da autonomia e satisfação (Rego \& Pina e Cunha, 2003).

De acordo com Zhu et al. (2013), os líderes transformacionais encorajam os seus colaboradores a esclarecerem sempre as suas dúvidas, a procurarem ser melhores na sua função e a usarem os recursos que têm à sua disposição para implementarem soluções inovadoras. Ao estimularem ideias inovadoras, os líderes estão também a incluir os funcionários no processo de tomada de decisão, criando laços e levando a que os colaboradores tenham um maior compromisso com o seu trabalho (Zhu et al., 2013). 0 facto de a liderança transformacional facilitar a mudança organizacional pode estar relacionado com uma maior satisfação com a sua chefia por parte dos colaboradores, uma vez que esta se preocupa com as motivações e crenças individuais (Pina e Cunha et al., 2014).

Se, por um lado, o estudo da liderança transformacional é relevante para se conhecerem os mecanismos de influência que promovem o desenvolvimento e autonomização dos colaboradores (Howell \& Avolio, 1993; Kovjanic et al., 2013), o estudo da liderança transacional é de extrema importância para aumentar o conhecimento acerca dos processos de motivação dos colaboradores de modo a atingirem os seus próprios objetivos (Rego \& Pina e Cunha, 2003).

Liderança Transacional. A liderança transacional é uma abordagem direcional que se caracteriza por uma relação de liderança em que a chefia direta motiva os colaboradores a lutarem pelos seus próprios interesses, utilizando a autoridade hierárquica e as regras para alcançarem os seus objetivos préestabelecidos (Avolio et al., 2009; Bass et al., 2003).

Os líderes transacionais fazem uso de recompensas com o objetivo de conseguirem a lealdade e submissão dos seus funcionários. Os colaboradores têm os seus desejos concedidos, assim como as suas necessidades satisfeitas, se desempenharem as tarefas pretendidas pelo seu superior e se tiverem o rendimento que o último solicitara (Bass, 1999; Rego \& Pina e Cunha, 2003). Quando os colaboradores têm a perceção de que os seus superiores diretos têm comportamentos que são caracterizados como transacionais (i.e., autorizar um pedido de um funcionário apenas quando está mencionado no contrato formal, ou quando é de seu próprio interesse enquanto líder), eles deixam de seguir o líder (Gomes \& Cruz, 2007). Gomes e Cruz (2007) afirmam ainda que os colaboradores deixam de se sentir comprometidos com a organização, tendo assim como principal objetivo lutar pelos seus interesses, trabalhando com o líder, com a finalidade de alcançarem reconhecimento e recompensas (Rego \& Pina e Cunha, 2003).

\section{Satisfação dos Colaboradores face ao Líder}

No que concerne à satisfação laboral, esta caracteriza-se como um fator indispensável à organização, tanto relativamente à produtividade dos indivíduos como à sua realização pessoal (Silva, 1998). A mesma pode ser descrita como um rumo emocional experienciado pelo colaborador em relação ao seu trabalho, sendo igualmente caracterizada como uma consequência do mesmo (Carlotto \& Braun, 2014; Holloway \& Wampold, 1983).

De acordo com Peiró et al., (1991), por norma, todos os sujeitos têm expetativas sobre o seu ambiente de trabalho e têm ideias pré-definidas de como pretendem clarificar algumas situações. No entanto, isto nem sempre acontece, ou seja, quando as ideias criadas pelos sujeitos são confrontadas com a realidade, manifestam-se emoções e comportamentos que darão origem a uma maior ou menor satisfação por parte dos colaboradores (Peiró et al., 1991). A satisfação e a insatisfação, consideradas 
como respostas emocionais, são visíveis em diversas ações que podem ter carácter positivo ou negativo (Carlotto \& Braun, 2014).

A definição de satisfação proposta por Holloway e Wampold (1983) é complementar às anteriores, ajudando a perceber os mecanismos através dos quais a satisfação emerge e se estabelece, i.e., uma reação dos supervisionados à perceção das qualidades pessoais e performance percebidas dos seus supervisores, ao comportamento destes durante a supervisão e ao nível de conforto quando expressam as suas ideias durante a supervisão. Como resultado, a satisfação com o supervisor é a perceção que o supervisionado tem das qualidades do seu supervisor e dos meios que facilitam o seu crescimento e desenvolvimento profissional (Ladany et al., 1999).

A satisfação dos colaboradores face ao líder, segundo Neves (2013), é um dos fatores com maior impacto na satisfação laboral, o que é também defendido por outros autores como Watson (2009), que propõem que a satisfação dos colaboradores face ao líder é a parte da satisfação laboral mais importante, estando relacionada com a ligação positiva construída entre os colaboradores e os líderes diretos. No que à liderança situacional diz respeito, esta relação positiva deve construir-se e manter-se graças à capacidade da chefia direta para utilizar tanto a liderança transformacional como a transacional, em função da natureza da tarefa ou das exigências do contexto. Sendo a satisfação com a chefia direta uma atitude positiva que emerge da perceção de que a chefia cumpre bem o seu papel, espera-se que os líderes que melhor utilizam as duas formas de liderança desenvolvam nos seus subordinados ideias mais positivas sobre o seu desempenho enquanto supervisores. Desta forma, não é suficiente utilizar diferentes estilos de liderança, é igualmente pertinente ajustar de forma flexível os comportamentos de liderança aos requisitos das tarefas, que mudam rapidamente ao longo do tempo. Além disso, os comportamentos do supervisor devem ser consistentes numa abordagem de liderança (MarquesQuinteiro, 2014). Sendo assim, é esperado que:

Hipótese 1: A liderança situacional está positivamente relacionada com a satisfação dos colaboradores face ao líder.

\section{Locus de Controlo}

Rotter (1966) defende que o locus de controlo pode ser considerado como um conjunto de expetativas em relação à quantidade de controlo que os indivíduos percecionam ter sobre as situações, ou seja, a forma como o indivíduo perceciona a relação entre o seu esforço e a consequência do mesmo. Torna-se pertinente referir as diferenças entre o locus controlo interno e o locus controlo externo, pois, segundo Rotter (1966), quando um indivíduo tem a perceção de que o reforço se deve apenas a si - que tem o poder de controlar sempre a situação e as outras pessoas -, devemos percecioná-lo como um sujeito que tem um locus de controlo interno. Já quando o sujeito tem a perceção de que não consegue controlar o seu ambiente, acreditando que tudo o que lhe acontecesse é devido a fatores externos a si mesmo - como outras pessoas, entre outros motivos externos ao sujeito -, este é percecionado como tendo um locus de controlo externo.

Curiosamente, a investigação sobre o locus de controlo sugere que tanto a dimensão externa como a dimensão interna possam coexistir num mesmo indivíduo e que a sua manifestação está relacionada com fatores contextuais como o ambiente de trabalho e os comportamentos de liderança da chefia direta (e.g., De Hoogh \& Den Hartog, 2009; Galvin et al., 2018). Sendo o locus de controlo uma variável cuja manifestação e relação com outras variáveis está intimamente relacionada com fatores contextuais, o mesmo indivíduo poderá exibir diferentes níveis de locus de controlo interno e externo em situações díspares. No presente estudo, a variável que se espera estar relacionada com estas diferenças é a liderança situacional.

Runyon (1973) verificou no seu estudo que os funcionários com um locus de controlo interno tinham preferência por uma liderança participativa (transformacional), enquanto os funcionários com um locus de controlo externo tinham preferência pela liderança diretiva. Segundo Rahman (2018), quando o líder apresenta um estilo de liderança mais transformacional, o colaborador desenvolverá um locus de controlo mais interno. Num estudo realizado por Škudienè et al., (2018), estes autores também encontraram evidências de que existe uma relação forte entre a liderança transformacional e o locus de controlo interno. Os mesmos autores verificaram ainda, que entre as dimensões da liderança transacional, são as recompensas contingentes que têm uma associação significativa com o locus de controlo interno.

Em relação à liderança situacional, o líder para adaptar os seus comportamentos aos colaboradores deve conhecer as características de personalidade dos mesmos, sendo mais transformacional ou mais transacional em função do que os indivíduos necessitam (Grint, 2011). Estas necessidades podem estar relacionadas com a tarefa ou com características de personalidade, como por exemplo o locus de controlo (Epitropaki \& Martin, 2013). Perante um colaborador com um locus de 
controlo externo, se o líder atribuir a falta de bons resultados a si mesmo, os níveis de satisfação com a chefia serão mais elevados (Johnson et al., 1984).

No entanto, os indivíduos com um locus de controlo interno têm outras necessidades. Runyon (1973) afirma que os indivíduos com um locus de controlo interno têm níveis mais elevados de satisfação no trabalho e compromisso organizacional, sendo visível uma relação de qualidade e de confiança entre funcionários e supervisores. Responsabilizando-se mais pelo seu envolvimento na função, os indivíduos com locus de controlo interno podem sentir-se mais satisfeitos com a chefia direta porque, em primeiro lugar, estarão satisfeitos consigo próprios. Para além disso, a liderança situacional pode promover uma maior consciencialização do indivíduo face à sua própria forma de desempenhar a sua função, tornando inclusive clara a importância do papel do supervisor.

De acordo com os resultados encontrados por Rahman (2018), espera-se que o locus de controlo medeie a relação entre a liderança situacional e os níveis de satisfação dos colaboradores face ao líder, uma vez que, segundo este autor, a liderança situacional se encontra significativamente e positivamente associada com a satisfação e o locus de controlo medeia a mesma, pois encontra-se relacionado com os comportamentos positivos/negativos que os colaboradores têm face à chefia.

Hipótese 2: 0 locus de controlo externo tem um papel mediador na relação entre a liderança situacional e a satisfação dos colaboradores face ao líder.

Hipótese 3: 0 locus de controlo interno tem um papel mediador na relação entre a liderança situacional e a satisfação dos colaboradores face ao líder.

A Figura 1 ilustra o modelo de investigação em análise.

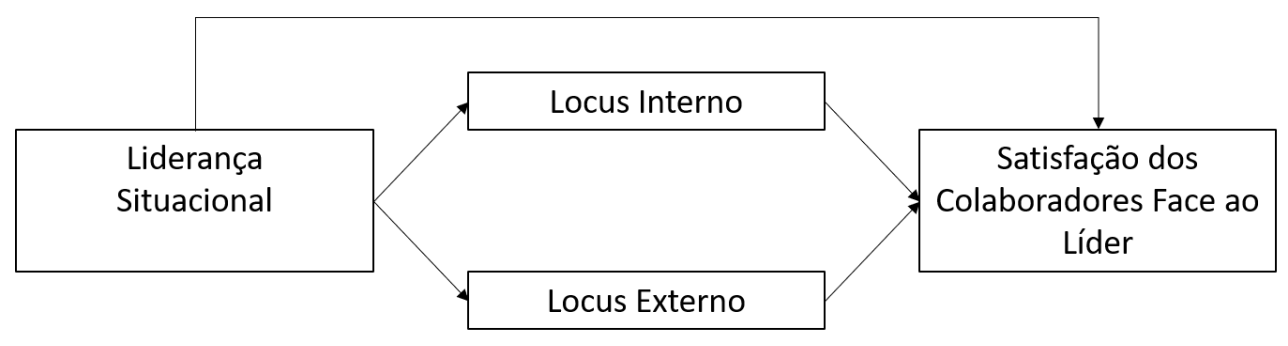

Figura 1: Modelo de Investigação

\section{MÉTODO}

\section{Procedimento}

Colaboraram neste estudo, de forma voluntária, 149 participantes. Todos eles foram considerados nas subsequentes análises estatísticas, uma vez que reuniam a única condição à participação neste estudo (estarem a trabalhar à data da recolha dos dados em organizações sediadas no território português e terem supervisão direta). O processo de amostragem foi o não probabilístico, de conveniência e intencional, tipo snowball (D’Oliveira, 2007).

O questionário colocado na plataforma Qualtrics continha informação sobre o objetivo do estudo, o consentimento informado e assegurava a confidencialidade das respostas dadas pelos participantes. A sua divulgação foi feita via online, através de e-mail, redes sociais como Facebook e Linkedln, e sites de psicologia. O link do questionário foi ainda enviado para os recursos humanos de várias empresas, com o objetivo de conseguir mais respostas. A recolha de dados ocorreu entre os meses de fevereiro e maio de 2016.

\section{Participantes}

A amostra recolhida é constituída por participantes maioritariamente do género feminino, 67,80\% com idades compreendidas entre os 19 e os 78 anos de idade $(M=37,52$ e $D P=12,60)$. Em relação às habilitações literárias, verifica-se que o grau de Licenciatura Pré-Bolonha / Mestrado (Bolonha) é o que tem maior predominância de sujeitos com 38,30\% $(n=57)$, de seguida o atual ensino secundário com $34,20 \%(n=51)$ e com Bacharelato / Licenciatura com 12,80\% ( $n=19)$. Quanto ao tipo de contrato, o que apresentou maior percentagem de respostas foi o contrato a tempo integral permanente com $69,80 \%(n=$ 104), a tempo integral temporário com 10,10\% $(n=15)$, o tempo parcial temporário com $10,10 \%(n=$ 15), a tempo parcial permanente com $6,70 \%(n=10)$ e os subcontratados com 3,40\% $(n=5)$. Entre estes participantes, $14,10 \%(n=21)$ têm uma antiguidade na organização inferior a 1 ano, $10,10 \%(n=15)$ 
entre 1 a 2 anos, 10,70\% (n=16) entre 2 a 3 anos, 9,40\% (n = 14) entre 3 a 4 anos, 2,70\% (n= 4) entre 4 a 5 anos e $53,00 \%(n=79)$ superior a 5 anos. No que respeita à antiguidade na função, 15,40\% (n=23) têm uma antiguidade na função inferior a 1 ano, 11,40\% (n = 17) entre 1 a 2 anos, 10,70\% $(\mathrm{n}=16)$ entre 2 a 3 anos, 8,10\% (n=12) entre 3 a 4 anos, $4,00 \%(n=6)$ entre 4 a 5 anos e $50,30 \% \%(n=75)$ superior a 5 anos.

\section{Procedimento de análise de dados}

0 primeiro passo foi testar as qualidades métricas dos instrumentos utilizados neste estudo. A sua validade foi testada através de análises fatoriais confirmatórias com recurso ao software AMOS 24 for Windows. 0 procedimento foi de acordo com uma lógica de "geração de modelos" (Jöreskog \& Sörbom, 1993), considerando-se na análise do seu ajustamento, interactivamente os resultados obtidos: para o qui-quadrado $\left(\chi^{2}\right) \leq 5$; para o Tucker Lewis índex (TLI) > 0,90; para o goodness-of-fit índex (GFI) > 0,90; para o comparative fit índex (CFI) > 0,90; para o root mean square error of approximation (RMSEA) $\leq 0,08$. Procedeu-se seguidamente à análise da consistência interna de cada escala, através do cálculo do alfa de Cronbach, cujo valor deverá variar entre "0" e "1", não assumindo valores negativos (Hill \& Hill, 2002). Quanto ao estudo da sensibilidade, procedeu-se ao cálculo das diferentes medidas de tendência central, de dispersão e de distribuição para os diferentes itens das escalas utilizadas, efetuando assim o estudo da normalidade para todos os itens das diversas escalas. As hipóteses formuladas neste estudo foram testadas recorrendo à Macro Process 2.16 desenvolvida por Hayes (2013).

\section{Instrumentos}

Na realização do presente estudo, foi utilizado um questionário composto por quatro partes, a primeira com questões sociodemográficas e as últimas três por escalas psicológicas que pretendiam avaliar as três variáveis em estudo.

Para a categorização sociodemográfica da amostra, foram colocadas questões sobre o género, idade, habilitações académicas, tipo de contrato, antiguidade na organização e, por fim, antiguidade na função.

Quanto à operacionalização da liderança situacional, neste estudo assumiu-se que a mesma pode ser operacionalizada enquanto a coexistência, num mesmo indivíduo, com comportamentos de liderança transformacionais e transacionais, ajustando-se às necessidades de contexto, num modelo que, segundo Kerlinger (1986), os líderes podem usar em contexto laboral.

A liderança situacional pode, assim, resultar da média ponderada das perceções que os indivíduos têm acerca dos comportamentos de ambos os estilos de liderança que surgem como resposta ao que as organizações ou/e os colaboradores precisam. Desta forma, a liderança situacional foi medida com uma versão adaptada do questionário multifatorial de liderança (Bass, 1985), adaptado à população portuguesa por Salanova et al., (2011). Neste estudo utilizou-se a versão reduzida, constituída por 28 itens que se divide em duas subescalas: Liderança Transformacional e Liderança Transacional. Por sua vez, a Liderança Transformacional divide-se em cinco fatores: atributos idealizados (1, 2, 3 e 4) (e.g. "As pessoas sentem-se orgulhosas por trabalharem com ele"), comportamentos idealizados (5, 6, 7 e 8) (e.g. "Fala acerca das suas crenças e valores mais importantes"), motivação inspiracional (9, 10, 11 e 12) (e.g. "Fala de um modo otimista acerca do futuro"), estimulação intelectual $(13,14,15$ e 16$)$ (e.g. "Considera diferentes perspetivas quando resolve problemas") e consideração individualizada $(17,18,19$ e 20$)$ (e.g. "Trata os outros como indivíduos e não apenas como membros de um grupo"). A liderança Transacional divide-se em dois fatores: recompensas contingentes (21, 22, 23 e 24) (e.g. "Dá apoio aos outros em troca dos seus esforços") e gestão pela exceção ativa $(25,26,27$ e 28) (e.g. "Concentra a sua atenção na resolução dos erros, falhas e queixas"). De referir que os itens estão organizados numa escala de tipo Likert de cinco pontos que varia de "Nunca" (1) a "Frequentemente, se não sempre" (5).

A validade das duas subescalas foi testada através de uma análise fatorial confirmatória. No que se refere à Liderança Transformacional, confirmou-se a existência de cinco dimensões: atributos idealizados (itens 1, 2, 3); comportamentos idealizados (itens 5, 6, 7 e 8); motivação inspiracional (9, 10, 11 e 12); estimulação intelectual (14, 15 e 16) e consideração individualizada (17, 18, 19 e 20). De referir que houve a necessidade de se retirarem os itens 4 e 13 por apresentarem um baixo peso fatorial. Os índices de ajustamento obtidos são os adequados $\left(\chi^{2} / \mathrm{gl}=1,98 ; \mathrm{GFI}=0,85\right.$; CFI = 0,94; TLI = 0,93; RMSEA = 0,08; $P[$ rmsea $\leq 0,05]=0,001)$ (Marôco, 2014). Quanto à consistência interna, também apresenta um alfa de Cronbach no valor de 0,96, que pode ser considerado bom, o mesmo acontecendo com cada uma das dimensões, que é de 0,86 para os atributos individualizados, de 0,83 para os comportamentos idealizados, de 0,91 para a motivação inspiracional, de 0,78 para a estimulação intelectual e de 0,88 para a consideração individualizada (Hill \& Hill, 2002). 
Relativamente à liderança transacional, utilizaram-se apenas as dimensões recompensas contingentes e gestão pela exceção ativa. A dimensão gestão, pela exceção passiva, não foi incluída por esta não ter sido considerada na versão original de Bass (1985). Foram realizadas duas análises fatoriais confirmatórias a dois fatores e a um fator. Os resultados indicaram-nos que os índices de ajustamento a um fator $\left(\chi^{2} / \mathrm{gl}=1,74 ; \mathrm{GFI}=0,98\right.$; CFI =0,99; TLI =0,98; RMSEA =0,07; $\left.P[\mathrm{rmsea} \leq 0,05]=0,272\right)$ eram melhores do que os índices de ajustamento a dois fatores $\left(\chi^{2} / \mathrm{gl}=2,97\right.$; GFI = 0,93; CFI = 0,92; TLI = 0,88; RMSEA = 0,12; $P[$ rmsea $\leq 0,05]=0,002$ ) (Marôco, 2014), pelo que esta subescala será considerada como unidimensional. Retiraram-se os itens 25, 27 e 28 por apresentarem um baixo peso fatorial. Quanto à consistência interna também apresenta um alfa de Cronbach no valor de 0,86, que pode ser considerado bom (Hill \& Hill, 2002). No que respeita à liderança situacional (liderança transformacional e liderança transacional), o valor do alfa de Cronbach é de 0,97 , o que pode ser considerado muito bom.

Para medir a Satisfação da Equipa face ao Líder, recorreu-se à dimensão de Satisfação com a Supervisão, do instrumento de Satisfação Laboral S20/23 de Meliá e Peiró (1989), adaptado à população portuguesa por Pocinho e Garcia (2008). É constituída por seis itens, como por exemplo: "A proximidade e frequência com que é supervisionado(a).", e construída numa escala de tipo Likert de sete pontos, que pode ser classificada desde "Muito Insatisfeito" (1 ponto) até "Muito Satisfeito" (7 pontos). A sua validade foi testada através de uma análise fatorial confirmatória, na qual se obtiveram os índices de ajustamento adequados $\left(\chi^{2} / \mathrm{gl}=1,85 ; \mathrm{GFI}=0,97 ; \mathrm{CFI}=0,99 ;\right.$ TLI $=0,97$; RMSEA $\left.=0,08 ; P[\mathrm{rmsea} \leq 0,05]=0,220\right)$ (Marôco, 2014). Quanto à consistência interna, também apresenta um alfa de Cronbach no valor de 0,88 , que pode ser considerado bom (Hill \& Hill, 2002).

0 locus de controlo foi avaliado através da escala MASLOC (Multidimensional Academic-Specific Locus of Control) de Palenzuela (1988), traduzida e adaptada à população portuguesa por Barros (1992). Apesar de a escala ser do âmbito escolar, foram feitas alterações para o contexto organizacional. É uma escala de tipo Likert de nove pontos que variam, desde o "Completamente em desacordo" (1) e "Completamente de acordo" (9). É constituída por catorze itens distribuídos por três dimensões: externalidade ou sorte $(1,3,5,11$ e 12) (e.g. "O ter boas ou más avaliações depende da sorte no trabalho"), a contingência ou internalidade $(2,6,9$ e 10) (e.g. "As avaliações dependem da minha capacidade em desempenhar bem as tarefas") e não contingencial, externalidade ou desânimo $(4,7,8,13$, 14) (e.g. "Tanto vale trabalhar como não trabalhar, porque os supervisores vão acabar sempre por me dar avaliações negativas").

A validade desta escala foi testada através de uma análise fatorial confirmatória que nos confirmou a existência de três dimensões: externalidade ou sorte $(1,3,11$ e 12$)$, contingência ou internalidade $(2,6$, 9 e 10) e não contingencial, externalidade ou desânimo $(4,7,8,13)$. Foram retirados os itens 5 e 14 por apresentarem um baixo peso fatorial. Os índices de ajustamento obtidos foram os adequados $\left(\chi^{2} / \mathrm{gl}=\right.$ 1,77; GFI =0,91; CFI =0,95; TLI =0,94; RMSEA =0,07; $P[$ rmsea $\leq 0,05]=0,070)$. Quanto à consistência interna, também apresenta um alfa de Cronbach no valor de 0,88 , que pode ser considerado bom, 0 mesmo acontecendo com cada uma das dimensões, que é de 0,76 para a contingência ou internalidade, de 0,79 para externalidade ou sorte e de 0,80 para a não contingencial, externalidade ou desânimo, sendo que a consistência interna do locus de controlo interno (internalidade) é 0,76 , enquanto o locus de controlo externo (externalidade ou sorte e não contingencial, externalidade ou desânimo) é 0,86 (Hill \& Hill, 2002). Verificou-se ainda que nenhum dos itens que compõem os três instrumentos viola grosseiramente a normalidade.

\section{Variáveis de Controlo}

Das seis questões sociodemográficas, duas foram utilizadas enquanto variáveis de controlo. A escolha destas variáveis é justificada por evidência na literatura quanto ao seu papel. Segundo Montepare e Lachman (1989), a idade está relacionada com a satisfação, sentindo-se os participantes mais velhos mais satisfeitos com a sua chefia quando comparados com os mais novos. A variável género pode ser relacionada com a variável liderança, segundo Reuvers et al., (2008), líderes do género feminino e masculino podem ter os mesmos comportamentos no desempenhar das suas funções, mas a perceção dos colaboradores é de que os líderes do género masculino são mais eficazes a incutir comportamentos inovadores nos seus colaboradores do que as líderes do género feminino. No entanto, na perspetiva de Rahman (2018), os líderes do género feminino têm um estilo de liderança mais transformacional, enquanto os líderes do género masculino apresentam um estilo de liderança mais transacional.

\section{RESULTADOS}

Os resultados da Tabela 1 mostram uma correlação significativa e negativa entre a idade e o locus de controlo interno $(r=-0,36, p<0,01)$, verifica-se que a liderança situacional tem uma correlação significativa e positiva com o locus de controlo interno $(r=0,24, p<0,01)$, e com a satisfação face ao líder 
( $r=0,37, p<0,01)$. É também visível uma relação negativa entre a satisfação com o líder e o locus de controlo externo $(r=-0,39, p<0,01)$, e uma correlação positiva entre a satisfação com o líder e o locus de controlo interno $(r=0,46, p<0,01)$. Não foram encontradas correlações significativas entre a variável sociodemográfica género e as restantes variáveis.

Tabela 1. Médias, Desvio Padrão e Correlações entre variáveis sociodemográficas e as variáveis em estudo.

\begin{tabular}{lccccccc}
\hline & Média & Desvio padrão & $\mathbf{1}$ & $\mathbf{2}$ & $\mathbf{3}$ & $\mathbf{4}$ & $\mathbf{5}$ \\
\hline 1. Género & 1.34 & 0.52 & - & & & & \\
2. Idade & 37.42 & 12.59 & -0.02 & - & & & \\
3. Lid. Situacional & 3.16 & 0.45 & 0.01 & -0.07 & - & & \\
4. LC Externo & 2.43 & 0.76 & 0.08 & 0.15 & -0.08 & - & \\
5. LC Interno & 4.19 & 0.78 & 0.02 & $-0.36^{* *}$ & $0.24^{* *}$ & $-0.54^{* *}$ & - \\
6. Satisfação Líder & 3.58 & 0.87 & 0.01 & -.069 & $0.37^{* *}$ & $-0.39^{* *}$ & $0.46^{* *}$ \\
\hline
\end{tabular}
Nota. ${ }^{* *} p<0,01$.

Em relação ao teste de hipóteses, os resultados apresentados na Tabela 2 sugerem que a liderança situacional está relacionada de forma positiva e significativa com os níveis de satisfação dos colaboradores face ao líder (B =0,56; $S E=0,14 ; t=4,02 ; p<0,001)$.

Tabela 2. Resultados do modelo de mediação do Locus de Controlo Externo e Locus de Controlo Interno entre as variáveis

\begin{tabular}{|c|c|c|c|c|c|c|}
\hline & \multirow{2}{*}{ B } & \multirow{2}{*}{ SE } & \multirow{2}{*}{$\mathbf{t}$} & \multirow{2}{*}{$p$} & \multicolumn{2}{|c|}{ IC 95\% } \\
\hline & & & & & LI & LS \\
\hline \multicolumn{7}{|c|}{ Efeitos diretos totais $\mathrm{R}^{2}=0.32, \mathrm{MSE}=0.53, \mathrm{~F}(3,143)=22.06, p=<0.001$} \\
\hline Constante & 1.20 & 0.64 & 1.87 & 0.063 & -0.07 & 2.47 \\
\hline Liderança Situacional & 0.56 & 0.14 & 4.02 & $<.001$ & 0.28 & 0.83 \\
\hline LC Externo & -0.26 & 0.09 & -2.77 & 0.006 & -0.45 & -0.08 \\
\hline LC Interno & 0.30 & 0.09 & 3.17 & 0.002 & 0.11 & 0.49 \\
\hline \multicolumn{7}{|c|}{ Efeitos parciais das variáveis de controlo } \\
\hline Género & 0.05 & 0.12 & 0.44 & 0.67 & -0.19 & 0.29 \\
\hline Idade & 0.01 & 0.01 & 0.13 & 0.90 & -0.01 & 0.01 \\
\hline \multicolumn{7}{|c|}{ Efeitos indiretos com correção Bootstrap } \\
\hline Efeito (LC Externo) & .04 & .04 & - & - & -.05 & .13 \\
\hline Efeito (LC Interno) & .12 & .05 & - & - & .04 & .23 \\
\hline
\end{tabular}

Nota. Correção Bootstrap = 5,000. LI = Limite inferior; LS = Limite superior.

\section{DISCUSSÃo}

O presente estudo tinha como principal objetivo verificar se a relação entre a liderança situacional exercida pelo líder e os níveis de satisfação dos colaboradores face ao líder é mediada pelo locus de controlo dos colaboradores.

O teste das hipóteses desta investigação sugere que a liderança situacional está positivamente relacionada com a satisfação dos colaboradores face ao líder e que o locus de controlo externo não é mediador desta relação, enquanto o locus de controlo interno medeia a relação anteriormente descrita. Estudar a relação entre a liderança situacional da chefia direta e satisfação com a supervisão, assim como se esta relação é mediada pelo locus de controlo dos colaboradores torna-se fundamental, de modo a aumentar o conhecimento existente sobre a forma como as características dos colaboradores interagem para explicar a satisfação face ao líder em contexto organizacional. Considerando que o estilo de liderança utilizado pelos superiores hierárquicos e os níveis de satisfação para com o trabalho demonstrado pelos colaboradores têm grande importância para o desempenho dos mesmos (Kovjanic et al., 2013), o estudo destas variáveis assume uma grande relevância.

Relativamente aos resultados do teste das hipóteses da presente investigação, estes mostraram que existe uma relação positiva e significativa entre a liderança situacional e a satisfação dos colaboradores face ao líder (H1). Estes resultados vão ao encontro do que é defendido por Tyssen et al., (2013), segundo o qual diferentes estilos de liderança podem ser eficazes, dependendo do momento que a organização está a viver. Os mesmos estão ainda alinhados com as ideias de Smith (2015), que defende 
que os estilos de liderança transacional e transformacional se complementam de forma a assegurar a eficácia da liderança.

Relativamente ao efeito mediador do locus de controlo na relação entre a liderança situacional e a satisfação dos colaboradores face ao líder, foram formuladas duas hipóteses, ou seja, (H2) o locus de controlo externo tem um papel mediador positivo na relação entre a liderança situacional e a satisfação dos colaboradores face ao líder, e (H3) o locus de controlo interno tem um papel mediador positivo na relação entre a liderança situacional e a satisfação dos colaboradores face ao líder.

A hipótese 2 não foi confirmada no presente estudo. Os resultados da presente investigação sugeriram a ausência de um efeito significativo por parte do locus de controlo externo, indo ao encontro dos resultados obtidos num estudo realizado por Škudienė et al., (2018), uma vez que estes autores não encontraram uma relação significativa entre o estilo liderança e o locus de controlo externo. A hipótese 3 foi confirmada, o que é corroborado pelo estudo de Galvin et al., (2018), onde é visível que o locus de controlo interno está relacionado com algumas variáveis do contexto laboral, entre as quais a satisfação no trabalho e o compromisso organizacional. Segundo Epitropaki e Martin (2013), o estilo de liderança adotado pela chefia e as características individuais dos colaboradores, tal como o locus de controlo, (Farmer, et al., 1997) determinam a satisfação dos últimos face ao líder.

Em suma, os resultados da presente investigação suportam a primeira e a terceira hipótese e rejeitam a segunda hipótese.

\section{Implicações teóricas e práticas}

O contributo do presente estudo para o desenvolvimento da literatura é importante, uma vez que os resultados demonstraram e existência de uma relação positiva entre a liderança situacional e a satisfação face ao líder, isto é, o líder não deve adotar sempre comportamentos de um determinado estilo de liderança conforme a sua própria personalidade. Deve sim, optar por ajustar os seus comportamentos de liderança às necessidades dos colaboradores e da organização.

Igualmente importante, foi ter-se verificado que o locus de controlo interno medeia a relação entre a chefia direta e a satisfação que o colaborador tem face ao líder, demonstrando assim que os níveis de satisfação face ao líder não estão apenas dependentes dos comportamentos adotados pela chefia, mas também estão relacionados com características de personalidades dos colaboradores como o locus de controlo.

O presente estudo trouxe algumas contribuições para as organizações pois foi testada a relação entre a variável liderança situacional e satisfação com o supervisor. A literatura existente fala-nos apenas de uma relação estatisticamente significativa entre a liderança transformacional e a satisfação com o supervisor e neste estudo demostrou-se que diferentes estilos de liderança levam a bons níveis de satisfação com o Supervisor, porque os estilos de liderança completam-se, dependendo do momento que a organização está a passar (Tyssen et al., 2013).

\section{Limitações e direções futuras}

Este estudo apresentou algumas limitações que podem ser resolvidas em investigações futuras. Em primeiro lugar, deve-se referir o processo de recolha de dados, em que a amostra foi recolhida através de um processo de amostragem não probabilístico, por conveniência e intencional (tipo snowball), o que levou a que a amostra fosse considerada subjetiva, não sendo assim possível a generalização dos dados pela população (D’Oliveira, 2007).

Outra das limitações foi a reduzida dimensão da amostra, que pode ser explicada pela dimensão do questionário ou a falta de motivação da população laboral em geral para participar neste tipo de estudos.

0 facto de as medidas serem todas auto reportadas, pode levar ao risco da existência de outra limitação, como o enviesamento de método comum. Este enviesamento pode ocorrer devido a vários fatores, como o contexto em que ocorre a avaliação do instrumento, os itens ou até as próprias características que definem os itens. Logo, em estudos futuros, numa replicação da presente investigação e para prevenção do risco de enviesamento, como o instrumento utilizado é dividido em 4 secções - dados sociodemográficos, liderança, satisfação com o supervisor e locus de controlo -, as mesmas podem ser aplicadas em três momentos diferentes: numa semana os dados sociodemográficos com outra medida, e nas semanas seguintes uma medida por semana (Podsakoff et al., 2003).

Embora exista alguma falta de consenso na literatura pelo facto de a liderança situacional ser um modelo ou uma teoria na literatura (Graeff, 1997), é fundamental estudar-se a sua influência sobre os colaboradores das organizações. Esta falta de consenso deve ser analisada em estudos futuros.

Também seria interessante testar este mesmo modelo, mas tendo em conta o desempenho como variável dependente. Isto permitir-nos-ia testar em que medida a relação positiva entre a liderança 
situacional e a satisfação poderiam, por sua vez, estar positivamente relacionadas com o desempenho no local de trabalho (Kovjanic et al., 2013).

\section{Conclusão Geral}

Em suma, o mercado laboral está em constante mudança e crescimento, sendo necessário que os colaboradores sejam positivos para um crescimento eficaz, sendo ainda mais importante a existência de boas relações entre colegas de trabalho, mais precisamente com a supervisão, uma vez que, quando os líderes se focam no relacionamento com os seus colaboradores, há efeitos positivos nos segundos (Smith, 2015).

\section{REFERÊNCIAS}

Avolio, B. J., Walumbwa, F. O., \& Weber, T. J. (2009). Leadership: Current theories, research, and future $\begin{array}{llll}\text { directions. Annual Review } & \text { Psychology, 60, } & \text { 421-449. }\end{array}$ https://doi.org/10.1146/annurev.psych.60.110707.163621

Barros, A. (1992). Atribuições Causais e Expectativas de Controlo do desempenho na matemática. Tese de Doutoramento. Braga, Universidade do Minho.

Bass, B. M. (1985). Leadership and performance beyond expectations. Free Press.

Bass, B. M. (1999). Two decades of research and development in transformational leadership. European Journal of Work and Organizational Psychology, 8(1), 9-32. https://doi.org/10.1080/135943299398410

Bass, B. M., Avolio, B. J., Jung, D. I., \& Berson, Y. (2003). Predicting unit performance by assessing transformational and transactional leadership. Journal of Applied Psychology, 88(2), 207-218. https://doi.org/10.1037/0021-9010.88.2.207

Burns, J.M. (1978). Leadership. Harper \& Row.

Carlotto, M. S., \& Braun, A. C. (2014). Atitudes no Ambiente de Trabalho: Motivação, Satisfação e Implicação Organizacional. In S. P. Gonçalves (Ed.), Psicossociologia do Trabalho e das Organizações: Princípios e Práticas. Lisboa: PACTOR - Edições de Ciências Sociais, Forenses e da Educação.

D’Oliveira, T. (2007). Teses e dissertações: recomendações para a elaboração e estruturação de trabalhos científicos (2- Ed.). RH Editora.

De Hoogh, A. H. B., \& Den Hartog, D. N. (2009). Neuroticism and locus of control as moderators of the relationships of charismatic and autocratic leadership with burnout. Journal of Applied Psychology, 94(4), 1058-1067. https://doi.org/10.1037/a0016253

Epitropaki, O., \& Martin, R. (2013). Transformational-transactional leadership and upward influence: The role of Relative Leader-Member Exchanges (RLMX) and Perceived Organizational Support (POS). The Leadership Quarterly, 24(2), 299-315. https://doi.org/10.1016/j.leaqua.2012.11.007

Farmer, S. M., Maslyn, J. M., Fedor, D. B., \& Goodman, J. S. (1997). Putting upward influence strategies in context. Journal of Organizational Behavior, 18, 17- 42. https://doi.org/10.1002/(SICI)10991379(199701)18:1<17::AID-J0B785>3.0.C0;2-9

Fiedler, F.E. (1964). A Theory of Leader Effectiveness. McGraw-Hill.

Galvin, B. M., Randel, A. E., Collins, B. J., \& Johnson, R. E. (2018). Changing the focus of locus (of control): A targeted review of the locus of control literature and agenda for future research. The Job Annual Review, 1-14. https://doi.org/10.1002/job.2275

Gomes, A. R., \& Cruz, J. (2007). Abordagem Carismática e Transformacional: Modelos Conceptuais e contributos para o exercício da Liderança. PSICOL.USP 18(3), $143 \quad$ - 161. https://doi.org/10.1590/S0103-65642007000300008.

Graeff, C. L. (1997). Evolution of situational leadership theory: A critical review. The Leadership Quarterly, 8(2), 153-170. https://doi.org/10.1016/S1048-9843(97)90014-X.

Grint, K. (2011). A history of leadership. In A. Bryman, D. Collinson, K. Grint, B. Jackson \& M. Uhl-Bien (Eds.), The SAGE handbook of leadership. Sage.

Hayes, A. F. (2013). An introduction to mediation, moderation, and conditional process analysis: A regression-based approach. Guilford Press.

Hill, M., \& Hill, A. (2002). Investigação por Questionário. Edições Sílabo.

Holloway, E. L., \& Wampold, B. E. (1983). Patterns of Verbal Behavior and Judgments of Satisfaction in the Supervision Interview. Jornal of Couseling Psychology, 30(2), 227-234. https://doi.org/10.1037/0022-0167.30.2.227

Howell, J. M., \& Avolio, B. J. (1993). Transformational leadership, transactional leadership, locus of control, and support for innovation: Key predictors of consolidated-business-unit performance. Journal of Applied Psychology, 78(6), 891-902. http://dx.doi.org/10.1037/0021-9010.78.6.891. 
Johnson, A. L., Luthans, F., \& Hennessey, H. W. (1984). The Role of Locus of Control in Leader Influence Behavior. Personnel Psychology, 37, 61-75. https://doi.org/10.1111/j.1744-6570.1984.tb02247.x

Jöreskog, K. G., \& Sörbom, D. (1993). LISREL8: Structural equation modelling with the SIMPLIS command language. Scientific Software International.

Judge, T. A., \& Piccolo, R. F. (2004). Transformational and transactional leadership: a meta-analytic test of their relative validity. Journal of Applied Psychology, 89(5), 755-768. https://doi.org/10.1037/0021-9010.89.5.755

Kerlinger, F. N. (1986). Foundatiuns of behavioral research (3rd. ed.). Holt, Rinehart, \& Winston.

Kovjanic, S., Schuh, S., \& Jonas, K. (2013). Transformational leadership and performance: Na experimental investigation of the mediating effects of basic needs satisfaction and work engagement. Journal of Occupational and Organizational Psychology, 86, 543-555. https://doi.org/10.1111/joop.12022

Ladany, N., Lehrman-Waterman, D., Molinaro, M., \& Wolgast, B. (1999). Psychotherapy supervisor ethical practices: Adherence to guidelines, the supervisory working alliance, and supervisee satisfaction. The Counseling Psychologist, 27, 443 475. https://doi.org/10.1177/0011000099273008

Marôco, J. (2014). Análise de Equações Estruturais: Fundamentos teóricos, software \& aplicações. (2ํㅡㅁ). ReportNumber, Lda.

Marques-Quinteiro, P. (2014). Liderança de Equipas Adaptativas. In Gonçalves, S.P. (Ed.). Psicossociologia do Trabalho e das Organizações: Princípios e Práticas. Lídel, Pactor.

McGrath, J. (1964). Social psychology: A brief introduction. Holt, Rinehart \& Winston.

Meliá, J. L., \& Peiró, J. M. (1989). La Medida de la Satisfacction Laboral en Contextos Organizacionales: El Cuestionario de Satisfaccion S20/23. Psicologemas, 5, $59-74$.

Montepare, J., \& Lachman, M. (1989). You're Only as Old as You Feel": Self-Perceptions of Age, Fears of Aging, and Life Satisfaction From Adolescence to Old Age. Psychology and Aging 4(1), 73-78. https://doi.org/10.1037/0882-7974.4.1.73

Neves, D. (2013). Liderança e satisfação dos enfermeiros com a supervisão (Tese de Mestrado, não publicada, Escola Superior de Enfermagem de Coimbra, Coimbra).

O'Meara, M. S., \& South, S. C. (2019). Big Five Personality Domains and Relationship Satisfaction: Direct Effects and Correlated Change Over Time. Journal of Personality. https://doi.org/10.1111/jopy.12468

Palenzuela, D. (1988). Control personal: Un enfoque itegrativo-mutidimensional. Manuscrito não publicado. Salamanca.

Peiró, M., Luque, O., Meliá L.\& Los Certales, F. (1991). El estrés de ensenar. Alfar.

Pina e Cunha, M., Rego, A., Cunha, R. C., Cabral-Cardoso, C., \& Neves, P. (2014). Manual de Comportamento Organizacional e Gestão, (7ํㅡ). Editora RH.

Pocinho, M. \& Garcia, J. (2008). Impacto psicosocial de la Tecnología de Información e Comunicación (TIC): tecnoestrés, daños físicos y satisfacción laboral. Acta Colombiana de Psicología, 11(2), 127139.

Podsakoff, P., Lee, J., \& Podsakoff, N. (2003). Common Method Biases in Behavioral Research: A Critical Review of the Literature and Recommended Remedies. Journal of Applied Psychology, 88 (5), 879903. https://doi.org/10.1037/0021-9010.88.5.879

Rahman, M. A. (2018). Influence of Styles of Women Leadership and Organization Culture on Locus of Control and Job Satisfaction of UIN Alauddin Makassar Lecturer. Integrated Journal of Business and Economics, 2(2), 1-13. https://doi.org/10.5281/zenodo.1258221

Rego, A, \& Pina e Cunha, M, (2003). A Essência da Liderança: Mudança x Resultados x Integridade, Teoria, prática, aplicações e exercícios de auto-avaliação. Editora RH, Lda.

Reuvers, M., Van Engen., M, Vinkenburg, C., \& Wilson-Evered, E. (2008). Transformational leadership and innovative work behaviour: Exploring yhe relevance of gender differences. Journal compilation, 17(3), 227-244. https://doi.org/10.1111/j.1467-8691.2008.00487.x

Rotter, J. B. (1966). Generalized expectancies for internal versus external control of reinforcement. Psychological Monographs: General And Applied,80(1), 1-28. https://doi.org/10.1037/h0092976

Runyon, K. E. (1973). Some Interactions Between Personality Variables and Management Styles. Journal of Applied Psychology, 57(3), 288 - 294. https://doi.org/10.1037/h0034723

Salanova, M., Lorente, L., Chambel, M, \& Martínez, I. (2011). Linking transformational leadership to nurses extra-role performance: the mediating role of self-efficacy and work engagement. Journal of Advanced Nursing, 1-11. https://doi.org/10.1111/j.1365-2648.2011.05652.x

Saleem, H. (2015). The impact of leadership styles on job satisfaction and mediating role of perceived organizational politics. Procedia Social and Behavioral Sciences, 172, 563-569. https://doi.org/10.1016/j.sbspro.2015.01.403 
Silva, R. B. (1998). Para uma análise da Satisfação no Trabalho. Sociologia: Problemas e práticas, 26, 149178. http://hdl.handle.net/10071/807.

Škudienė, V., Augutytė-Kvedaravičienė, I., Demeško N., \& Suchockis A. (2018). "Exploring the relationship between innovative work behavior and leadership: Moderating effect of locus of control". Organizations and Markets in Emerging Economies, 9, 17-40. https://www.ceeol.com/search/article-detail?id=678039

Smith, P. (2015). Leadership in Academic Health Centers: Transactional and Transformational Leadership. J Clin Psychol Med Settings, 22, 228-231. https://doi.org/10.1007/s10880-015-9441-8

Thompson, G., \& Vecchio, R. P. (2009). Situational leadership theory: A test of three versions. The Leadership Quarterly, 20(5), 837-848. https://doi.org/10.1016/j.leaqua.2009.06.014

Tyssen, A., Wald, A., \& Spieth, P. (2013). The challenge of transactional and transformational leadership in projects. International Journal of Project Management, 32, 365-375. https://doi.org/10.1016/j.ijproman.2013.05.010

Watson, L. (2009). Leadership's Influence On Job Satisfaction. Radiologic Technology, 80 (4), 297 - 308.

Zhu, W., Newman, A., Miao, Q., \& Hooke A. (2013). Revisiting the mediating role of trust in transformational leadership effects: Do different types of trust make a difference? The Leadership Quarterly, 24, 94-105. https://doi.org/10.1016/j.leaqua.2012.08.004

Historial do artigo

Recebido $\quad 01 / 2019$

Aceite $\quad 05 / 2020$

Publicado $\quad 08 / 2020$ 